\title{
La encarnación de la verdad y la política de la comunidad: Foucault y los cínicos ${ }^{1}$
}

\section{The embodiment of truth and the politics of community: Foucault and the cynics}

\author{
Vanessa LEMM \\ Universidad of New South Wales, Australia/Universidad Diego Portales, Chile
}

Recibido: 09/09/2013

Aceptado: 15/10/2013

\section{Resumen}

Este artículo investiga el análisis que Foucault lleva a cabo de la vida filosófica de los cínicos y de la parrêsia en El coraje de la verdad desde la perspectiva de la siguiente pregunta nietzscheana: ¿Cómo puede ser incorporada la verdad? Para considerar a la filosofía como una forma de vida y no meramente como una ciencia o una doctrina, la pregunta de cómo puede vivirse o materializarse la verdad en el cuerpo físico es, evidentemente, crucial. Mientras que tanto Foucault como Arendt pueden ser leídos como defensores de la vida filosófica por sus efectos ético-políticos, Arendt sostiene que la vida filosófica socrática es una vida que habilita una distancia con el cuerpo, en contraste, en el análisis de Foucault sobre los cínicos encontramos una idea de la vida filosófica en la que la verdad se revela o manifiesta en el cuerpo material de la vida. Este artículo recoge la lógica inmunitaria de la biopolítica de Esposito con el fin de sostener que la vida filosófica de los cínicos y su hablar franco (parrêsia) utilizan los recursos comunitarios de la encarnación para unificar la vida y la filosofía en una forma de vida cosmopolita.

Palabras clave: Foucault, Cínicos, Parrêsia, Nietzsche, Comunidad

${ }^{1}$ Este artículo está basado en una ponencia comunicada el 4 de septiembre del 2013 en el IV Coloquio Latinoamericano de Biopolítica, Bogotá, Colombia. Agradezco a la audiencia por sus preguntas y comentarios. 


\section{Abstract}

This article investigates Foucault's analysis of the philosophical life of the Cynics in The Courage of Truth from the perspective of the Nietzschean question: how truth can be incorporated or embodied? In order to consider philosophy as a form of life and not merely as a doctrine or a science, the question of how can truth be lived or materialized in the physical body is obviously crucial. Whereas both Foucault and Arendt can be read as defenders of the philosophical life because of its ethical-political effects, Arendt argues that the Socratic philosophical life is a life that allows a distance to the body. By way of contrast, in Foucault's analysis of the Cynics we find an idea of the philosophical life in which truth is revealed or manifest in the material body of life. This article takes up Esposito's immunitary logic of biopolitics in order to argue that whereas the Platonic-Socratic philosophical life exemplifies an ascetic ideal that reflects an inherently immunitarian idea of politics, the philosophical life of the Cynics uses the communitary resources of embodiment so as to unite life and philosophy in a cosmopolitical form of life.

\section{Keywords: Foucault, Cynics, Parrêsia, Nietzsche, Community}

Este artículo investiga el análisis que Foucault lleva a cabo de la vida filosófica de los cínicos en El coraje de la verdad desde la perspectiva de la siguiente pregunta nietzscheana: ¿Cómo puede ser incorporada o encarnada (einverleibt) la verdad? Para considerar a la filosofia como una forma de vida (bios theoretikos) y no meramente como una ciencia o una doctrina, la pregunta de cómo puede vivirse o materializarse la verdad en el cuerpo físico es, evidentemente, crucial. Como una forma de la verdadera vida (la vraie vie), la filosofía compite con la vida política (bios politikos) basada en la opinión. La competencia o agon entre la vida filosófica y la vida política constituye el trasfondo para el análisis de Foucault sobre la parrêsía en sus dos últimos volúmenes sobre el gobierno de sí y de los otros (Foucault, 2008 y 2009), esto es, el discurso franco o decir la verdad. Mientras que tanto Foucault como Arendt pueden ser leídos como defensores de la vida filosófica por sus efectos ético-políticos, Arendt sostiene que la vida filosófica socrática es una vida que habilita una distancia con el cuerpo, planteando de este modo una resistencia a aquello que Roberto Esposito ha llamado la clausura del cuerpo político sobre sí mismo, un aspecto característico de la política "totalitaria". ${ }^{2}$ En contraste, en el análisis de Foucault sobre los cínicos encontramos una idea de la vida filosófica en la que la verdad se revela

\footnotetext{
${ }^{2}$ Véase Hannah Arendt. 2011. La vida del espíritu. Barcelona: Édiciones Paidós. Roberto Esposito. Bios: biopolítica y filosofía. Buenos Aires: Amorrotu. 2006.
} 
o manifiesta en el cuerpo material de la vida (Foucault, 2009, 159). Más aún, Foucault instala la idea de la vida filosófica como la verdadera vida en los cínicos en contra del ideal platónico-socrático de la vida filosófica. Este artículo recoge la lógica inmunitaria de la biopolítica de Esposito con el fin de sostener que mientras la vida filosófica platónico-socrática ejemplifica un ideal ascético que refleja una idea de la política intrínsecamente inmunitaria, la vida filosófica de los cínicos utiliza los recursos comunitarios de la encarnación para unificar la vida (zoe) y la filosofía en una forma de vida (bios) cosmopolita. Foucault vio en este ideal de vida filosófica los recursos para resistir el gobierno liberal moderno de la vida al abrir el horizonte de una nueva política de la comunidad.

\section{La encarnación de la verdad}

En Nietzsche, la pregunta por la verdad es inseparable de la pregunta por la vida y, en efecto, el valor de la verdad sólo puede determinarse de cara al estándar de la vida biológica. Nietzsche invierte la comprensión tradicional de la filosofía cuando afirma que la verdad no tiene un valor en sí misma y que su valor depende, alternativamente, de si acaso ella aumenta o disminuye el poder de la vida. Esta afirmación tiene importantes implicancias para la comprensión que Nietzsche tiene de la filosofía y de la figura del filósofo. La vida del filósofo (bios) y su discurso sobre la verdad no se entienden más como cosas separadas: la verdad no es más el objeto de una ciencia o doctrina, sino una forma de vida en la que el pensamiento y la vida (zoe) deben ser considerados en su unidad. ${ }^{3}$ En su descripción de las características generales de los cínicos, Foucault establece un punto similar al subrayar que los cínicos fueron los primeros en plantear el problema de la naturalidad o vitalidad de la vida filosófica (Foucault, 2009, 155). En los cínicos, la práctica de la filosofía viene de la mano con la tarea de manifestar la verdad en y a través del cuerpo propio, es decir, en y a través de la visibilidad de la existencia material (Foucault, 2009, 159). En este punto, el desafío de la vida filosófica es restituir la cultura a la naturaleza, hacer volver (re-ducere) el bios a la zoe, siendo ésta la verdad de la zoe que se refleja en la forma de vida filosófica encarnada por los cínicos. Para los cínicos, la "reducción" del bios a la zoe es una parte esencial de su entendimiento del hablar franco (Foucault, 2009, 158). ${ }^{4}$ Sin embargo, esta reducción no debe ser entendida simplemente como un retorno a la naturaleza pues ella es, más bien, un retorno que revela a la zoe como bios, donde zoe debe entenderse como aquella fuerza que le proporciona

\footnotetext{
${ }^{3}$ Este punto ha sido desarrollado brillantemente por Jacques Derrida, Éperons: Les styles de Nietzsche. Paris: Flammarion, 1978.

${ }^{4}$ Para Foucault, la reducción de la vida a sí misma es una de las características principales de la forma de vida de los cínicos. Sin embargo, en su interpretación de los cínicos, Foucault no distingue explícitamente entre bios y zoe.
} 
estilo y forma a la vida (Foucault, 2009, 159). Por otra parte, esta forma de vida (este bios de la zoe) refleja la manera en la que la vida se torna visible en el cuerpo y los gestos de los cínicos. Los cínicos convierten a la vida en el vehículo de la verdad y a la verdad en el vehículo de la vida, dando lugar a una comunión perfecta entre la vida y la verdad en la que el cuerpo da forma a la verdad y la verdad da forma al cuerpo. Foucault se refiere a esta relación entre la vida, la verdad y el cuerpo como una manifestación de la verdad por el cuerpo, una aletheia de la verdad (aléthurgie) (ibíd.). ${ }^{5}$

Nietzsche tematiza la reducción del bios a la zoe bajo el topos del homo natura: la retraducción del ser humano a la naturaleza que encontramos en el aforismo 230 de Más allá del bien y del mal. ${ }^{6}$ De acuerdo a Nietzsche, los humanos no pueden soportar la idea de que sus así llamados logros culturales no sean productos de la civilización humana, esto es, el resultado de una emancipación de la naturaleza, sino más bien artefactos de la naturaleza reflejando las necesidades de la vida. Para los humanos, la idea de estar sujeto a las necesidades de la vida socava su sentido de la libertad y su necesidad de dominar y gobernar sobre la naturaleza. De ahí su deseo de engañarse y engañar sobre el "terrible texto básico homo natura [schreckliche Grundtext homo natura]" (MBM 230). Nietzsche concibe al filósofo del espíritu libre como alguien cuya pasión

\footnotetext{
${ }^{5}$ Para Foucault, la mayor parte de la recepción de los cínicos durante sus años no comprendía la cuestión de la aléthurgie cínica. Esta recepción representa típicamente la filosofía de los cínicos com un ejemplo de individualismo radical. En particular, Foucault remite a los trabajos de Klaus Heinrich, Parmenides und Jona: Vier Studien über das Verhältnis von Philosophie und Mythologie. Frankfurt: Surhkamp Verlag, 1966; Paul Tillich, The Courage to Be. New Haven: Yale University Press, 1952; y Arnold Gehlen, Moral und Hypermoral: Eine pluralistische Ethik. Frankfurt: Athenäum Verlag, 1969. Para Heinrich, los cínicos encarnaban la "autoafirmación (Selbstbehauptung) del individuo" en su lucha por la auto-conservación (Heinrich, Parmenides, 142); Tillich ve en los cínicos principalmente un ejemplo "inconformismo radical" (Tillich, Courage, 113); y Gehlen sostiene que incluso su cosmopolitismo no es sino "el reverso (Kehrseite) de su individualismo" (Gehlen, Moral, 23). Según Foucault, esta recepción no logra reconocer lo que a su juicio es la contribución más importante de los cínicos a la historia del pensamiento, a saber, un ejemplo del hablar franco (parrêsia) donde la vida material manifiesta la verdad como su expresión directa (Foucault, 2009, 166). Vale la pena notar que Peter Sloterdijk, a quien Foucault menciona pero admite no haber leído en el momento en que preparaba y dictaba su curso, hace una afirmación similar cuando sostiene que "el cinismo da a la pregunta de cómo se dice la verdad un nuevo giro" (Peter Sloterdijk, Crítica de la razón cínica. Madrid: Editorial Siruela, 2005), 179. Y también: "la aparición de Diógenes señala el momento dramático en el proceso de la verdad de la temprana filosofía europea" (Sloterdijk, Crítica de la razón cínica, 176).

${ }^{6}$ Friedrich Nietzsche, Más allá del bien y del mal: Preludio de una filosofía del futuro. Alianza Editorial, 2007. En lo que sigue, me apoyo en las siguientes abreviaciones estandarizadas de la obra de Nietzsche: KSA=Sämtliche Schriften, Kritische Studienausgabe in 15 Bänden, eds. Giorgio Colli y Mazzino Montenari (las referencias proporcionan el número de volumen seguido del número del fragmento relevante y cualquier aforismo relevante). Todas las traducciones de los fragmentos de la KSA son míos. Las siguientes abreviaciones van seguidas del número del aforismo; $\mathrm{MBM}=$ Más allá del bien y del mal; $\mathrm{GC}=$ La gaya ciencia; $\mathrm{GM}=$ Sobre la genealogía de la moral; OSV=Opiniones y sentencias varias; $\mathrm{HV}=$ Sobre la utilidad y el perjuicio de la historia para la vida; $\mathrm{HH}=$ Humano, demasiado humano.
} 
por la verdad y el conocimiento busca "retraducir, en efecto, el hombre a la naturaleza" (MBM 230). Lo que caracteriza a estos espíritus libres es una "desenfrenada honestidad (ausschweifende Redlichkeit)" que nos recuerda a los cínicos de Foucault y su esfuerzo por alcanzar una continuidad de comunidad entre la naturaleza (vida) y la verdad. Tanto para los cínicos de Foucault como para los espíritus libres de Nietzsche, la afirmación de las necesidades de la vida es el vehículo de la liberación y del cultivo que supera la necesidad de libertad como dominación propia del ser humano. Tal como los cínicos, Nietzsche sostiene que esta nueva verdad sobre el homo natura influirá en una "transformación (Umwandlung) del ser humano" (KSA 9:11[141]), ya que revela que afirmar las necesidades de la vida libera al ser humano para crear y re-crear continuamente sus propias condiciones de existencia más allá de la lucha por la auto-conservación (para la dominación) en dirección de una vida justa y común.

La encarnación de la verdad en los cínicos invierte la comprensión tradicional de la vida filosófica como verdadera vida. Esta inversión también es tematizada por Nietzsche en el aforismo 11 de La gaya ciencia al formular por primera vez la pregunta de cómo puede encarnarse la verdad. En este aforismo, Nietzsche afirma que "[c]ontinúa siendo una tarea completamente nueva, que precisamente ahora comienza a alborear ante los ojos del hombre y es apenas perceptible con nitidez: hacerse cuerpo [einzuverleiben] con el saber y hacerlo instintivo - ¡una tarea que será vista solamente por aquellos que han entendido que hasta ahora sólo nuestros errores se habían hecho cuerpo [einverleibt], y que toda nuestra claridad sobre nosotros mismos se remite a errores! (GC 11). ${ }^{8}$ Según Nietzsche, al ser sujeto y objeto de una crítica radical de la civilización, el filósofo muestra que todo su canon de valores, tanto morales como epistemológicos, descansa en suposiciones falsas. Si hasta el momento la vida ha sido posible por medio de la encarnación de errores, el desafío del filósofo cínico es mostrar que la vida también puede ser elevada, literalmente, al encarnar la verdad o el conocimiento. Sólo cuando la verdad puede ser vivida y manifestada físicamente en y a través del cuerpo propio, ella constituye verdadero conocimiento en lugar de mera ilusión. En este punto, la imagen del cínico de Foucault es una figura ilustrada: la vida filosófica de los cínicos y su verdad se encuentra delante y más allá de la humanidad conduciéndola, de este modo, hacia su propia ilustración (Foucault, 2009, 159).

De acuerdo con Foucault, la tarea del filósofo de invertir todos los valores es una tarea política. Foucault enfatiza que los cínicos deben ser entendidos dentro del contexto más general de la crítica a la parrêsia política que se encuentra no sólo en los cínicos sino que también en Platón. Mientras que la parrêsia política ejemplificada por el hom-

Friedrich Nietzsche, Sämtliche Werke. Editado por Colli y Montinari, Kritische Studienausgabe in 15 Bänden. Berlin: de Gruyter Verlag, 1988.

${ }_{8}$ Friedrich Nietzsche, La ciencia jovial. Trad. José Jara. Caracas: Monte Ávila Latinoamericana, 1999. 
bre democrático sólo refleja errores y opiniones compartidas, la vida filosófica necesita probarse como la única verdadera vida, esto es, como la única forma de vida que tiene acceso a la verdad. Los cínicos complican este desafío político al afirmar que la parrêsia política sólo puede ser verdaderamente superada por una vida filosófica que encarne la verdad y no por una vida filosófica en la que la verdad y el cuerpo estén separados y se excluyan mutuamente - como en el ideal Platónico-Socrático de la vida filosófica (Foucault, 2009, 147). Desde mi perspectiva, lo que la parrêsia política y la PlatónicoSocrática tienen en común, es que en sus constructos políticos la verdad figura como un dispositivo inmunitario. ${ }^{9}$ La parrêsia Platónico-Socrática es un medio que separa la vida de la verdad, la naturaleza de la cultura, y el animal del humano. La parrêsia democrática funciona de un modo similar al separar la diferencia de la igualdad, la individualidad de la comunidad, la alteridad de la identidad, y la polis de los "bárbaros". Alternativamente, sostengo que en los cínicos (y en Nietzsche) el hablar franco es una función de comunidad en la que la vida y la verdad, la diferencia y la igualdad, y la alteridad y la identidad, son entendidas como partes de una continuidad compartida de la vida, es decir, como elementos de una política de la comunidad. ${ }^{10}$

En Nietzsche, la tarea de encarnar la verdad se complica todavía más al considerar que los errores (Irrthümer) son ventajosos y preservan las especies (arterhaltend): "Parecía que con ella no se podía vivir y que nuestro organismo estaba ajustado de acuerdo con lo contrario a ella; todas sus funciones más altas, las percepciones de los sentidos y, en general, todo tipo de sensaciones, trabajaban con aquellos antiguos errores básicos ya incorporados [jenen uralt einverleibten Grundirrthümern]" (GC 110). Desde esta perspectiva, el poder del conocimiento no se determina según el grado de verdad que refleja sino más bien según su época, su grado de incorporación (Einverleibtheit) y su carácter en tanto condición de la vida (Lebensbedingung) (GC 110, véase en comparación KSA 11:34[247]). De modo similar al análisis de Foucault

9 Para una lectura diferente, véase Ottavio Marzocca, "Philosophical Parrêsia and Transpolitical Freedom," Foucault Studies 15 (2013): 129-147. De acuerdo a Marzocca, las parrêsias cínica y socrática son comparables en la medida en que ambas "permanecen cercanas a la práctica de la ciudadanía activa" (135).

${ }^{10}$ Desde mi perspectiva, el problema con las caracterizaciones de los cínicos llevadas a cabo por Heinrich y Gehlen, es que malinterpretan su radicalización del individualismo. La filosofía de los cínicos no refleja un intento por preservar al individuo, como sostiene Heinrich (Heinrich, Parmenides, 142). Por el contrario, ella ejemplifica la exasperación del individuo como el propietario de sí en vistas a restaurar una política de lo común. Aunque André Glucksman no entiende a los cínicos en términos de una relación invertida entre inmunidad y comunidad, es interesante notar que describe a Diógenes como "inmune" frente a la reducción de su vida filosófica a una suerte de "testamento académico": "el cinismo no es un diogenismo. Más modo de vida que doctrina, éste no se deja condensar en un dogma y cuando se deja, encuentra de inmediato el equívoco (le cynisme n'est pas un diogènisme. Plus mode de vie que doctrine, il ne se laisse pas condenser en dogme et quand il s'y prête, il retrouve aussitôt l'équivoque)" (André Glucksmann, Cynisme et passion. Paris: Bernard Grasset, 1981), 128. 
sobre los cínicos, el filósofo en Nietzsche se enfrenta a una tarea imposible: él o ella busca encarnar la verdad de un modo tal que la verdad se vuelva manifiesta en el cuerpo de la vida. Sin embargo, el cuerpo mismo de la vida no es capaz de una encarnación tal, esto es, de vivir con la verdad. Puesto que la verdad destruye la vida, la vida necesita, más que la verdad, errores e ilusiones. O bien, en palabras de Nietzsche, los "nuevos discernimientos [neue Erkenntnis]" del filósofo son peligrosos y "perjudiciales [schädigend]" para la vida (KSA 9:11[320]). Esta es la razón por la cual emprender la tarea de encarnar el conocimiento requiere, ante todo, coraje: el coraje de exponer la propia vida al peligro de la verdad, incluso si ello implica arriesgar la vida, es decir, su muerte. Este desafío, no cabe duda, nos recuerda al heroísmo filosófico enfatizado por Foucault en su caracterización general de los cínicos (Foucault, 2009, 183-196).

Desde esta perspectiva Nietzscheana, la vida política ya incorpora profundamente los errores que preservan la vida en la forma de sus opiniones dominantes o principios de legitimidad. En la contienda contra la vida política, la vida filosófica se enfrenta al dilema de tener que probar lo imposible, es decir, el filósofo necesita mostrar que la encarnación de su verdad eleva más la vida que la vida política y los errores preservadores de vida que ella tiene profundamente incorporados. El filósofo prevalece en esta lucha si puede demostrar que la necesidad del "error" puede ser superada. Superar quiere decir aquí, literalmente, superar una forma de vida política para hacer aparecer otranueva y alterada. Mientras que la primera es cerrada e inmune a la naturaleza y la vida no-humana, la segunda es una vida política abierta a la variedad del cosmos. El filósofo cínico sostiene una visión cosmo-política de la vida humana frente a la identidad de la política de la polis. ${ }^{11}$ En palabras de Foucault, el filósofo prevalece cuando puede mostrar que la verdadera vida es una vida alterada y alteradora: "la vrai vie est une vie autre [la veradera vida es una vida otra]" (Foucault, 2009, 226ss). Más allá de la crítica de la civilización, la creación de una vida otra y alterada constituye el aspecto afirmativo de la

${ }^{11}$ Si el cosmpolitismo de los cínicos no es otra cosa que "el reverso (Kehrseite) de su individualismo", como sostiene Gehlen (Gehlen, Morals, 23), esto sólo es así en la medida en que este "individualismo" es el reverso de una idea inmunitaria del yo que es escindida del otro e integrada en una idea comunitaria del yo, inseparable de y vinculada con la vida del cosmos. Sobre el cosmopolitismo de los cínicos, véase también Marie-Odile Goulet-Cazé, "Un syllogisme stoïcienne sur la loi dans la doxographie de Diogène le Cynique a propos de Diogène Laërce VI 72," Rheinisches Museum für Philologie 115(1982): 214-240, quien sostiene que el cosmopolitismo en los cínicos no es una llamada positiva para la realización de una comunidad humana universal, sino un rechazo individualista de arreglos sociales y políticos específicos. Alternativamente, John Moles afirma que el cosmopolitismo de los cínicos es una idea positiva que no sólo remite a una comunidad de pares específica, sino de hecho a la idea más universal de comunidad que también incluye la vida de los animales. Moles ve en el "estado (polity) del cosmos" el "más noble de todos los estados (politeiai) filosóficos" - en efecto, de todos los estados políticos_ de toda la antigüedad" (John L. Moles, "Cynic Cosmopolitanism" en The Cynics: The Cynic Movement in Antiquity and its Legacy," eds. R. Bracht Branham and Marie-Odile Goulet-Cazé. Berkeley: University of California Press, 1996), 105-120, here 120. 
vida filosófica como una vida verdaderamente encarnada. Foucault capta la dimensión política de esta otra vida en la fórmula: "un vie autre pour un monde autre [una vida otra por un mundo transformado]" (Foucault, 2009, 264). Sin embargo, ni para los cínicos ni para Nietzsche puede haber una solución final al paradójico dilema de la encarnación de la verdad. Ambos entienden la tarea de manifestar la verdad en y a través de la propia existencia física como una continua experimentación sobre sí mismo, es decir, como un desafío ilimitado que necesita del yo para alterarse y alterar a otros continuamente y hacer que este mundo devenga un mundo transformado.

\section{Encarnación, Inmunidad y Comunidad.}

La afinidad que Foucault observa entre su intento de girar la vida filosófica hacia la alteridad y el intento de los cínicos de volver a la zoe se entiende mejor dentro del contexto de una concepción Nietzscheana de la vida como voluntad de poder. En su lectura reciente de la voluntad de poder, Esposito sostiene que para Nietzsche la vida es una pulsión irresistible de ser más, de superarse y llegar más allá de sí misma. La vida es voluntad de poder porque se orienta incesantemente hacia la exterioridad de la vida que transforma y excede continuamente los límites de su propio ser. Por lo tanto, la vida nunca es idéntica a sí misma ya que se niega y destruye a sí misma continuamente en su afán por auto-transformarse: "antes de ser en-sí, el cuerpo es siempre en contra, incluso de sí mismo". ${ }^{12}$ Para Esposito, el impulso de la vida (zoe) de trascenderse a sí misma para crear una forma de vida (bios) es también un orientarse hacia una vida común, o aquello a lo que Esposito se refiere como communitas. ${ }^{13}$ Sin embargo, dado el potencial auto-destructivo inherente a la orientación de la vida hacia la justicia y la comunidad, la vida necesita una estrategia de auto-preservación que la proteja de su devenir otra, es decir, de su alteración. Esta estrategia de auto-preservación es la estrategia de la inmunización, o lo que Esposito llama immunitas. Uno de los ejemplos más prominentes de la estrategia de inmunización mencionado por Esposito, es la concepción de Nietzsche del ideal ascético como aquello que simultáneamente niega y preserva la vida (GM III). ${ }^{14}$ De acuerdo a Nietzsche, el ideal ascético refleja una encarnación de la verdad que logra preservar la vida exitosamente a través de la negación, supresión y sujeción de los impulsos de la vida. En cuanto tal, el ideal ascético debilita o enferma a la vida en tanto voluntad de poder, convirtiendo a su verdad encarnada, de este modo, en un vehículo de

\footnotetext{
${ }^{12}$ Roberto Esposito, Bios. Biopolítica y filosofía. Buenos Aires: Amorrortu, 2006, 135.

${ }^{13}$ Roberto Esposito, Communitas: origen y destino de la comunidad. Trad. Carlo R. Molinari Marotto. Buenos Aires: Amorrortu, 2003.

${ }^{14}$ Friedrich Nietzsche, 1997. La genealogía de la moral. Trad. Andrés Sánchez Pascual. Madrid: Alianza, 1997.
} 
salud para la auto-preservación de lo débil. Nietzsche confirma que el ideal ascético ha convertido exitosamente a la negación (enfermedad) de la vida en una afirmación de la misma al hacer que lo negativo se vuelva productivo. Pero también advierte sobre la paradójica y auto-contradictoria naturaleza de la inmunidad. Finalmente, la encarnación de la verdad en el ejemplo del ideal ascético muestra que el intento por proteger la vida a través de la negación falla: en vez de preservar la vida por medio de la enfermedad, la enferma todavía más, terminando por destruir a la vida que tiene por objeto proteger (GM III: 13). En consecuencia, Esposito levanta la pregunta de si caso es posible preservar la vida de una manera distinta que a través de la inmunización.

Desde mi perspectiva, Nietzsche aborda directamente esta pregunta planteada por Esposito en sus concepciones inmunitaria y comunitaria de la encarnación. Como he sostenido en otro lugar, Nietzsche distingue entre dos concepciones diferentes de la encarnación que se oponen diametralmente: por una parte, tenemos a la encarnación como estrategia inmunitaria; y por otra, a la encarnación como estrategia de comunidad..$^{15}$ Cuando Nietzsche describe procesos de encarnación que desempeñan una función inmunitaria, recurre a una semántica de la apropiación (Aneignung) (OSV 317), ${ }^{16}$ como por ejemplo en MBM 259. Y alternativamente, cuando habla de la encarnación como estrategia de comunidad, se refiere a procesos de transformación creativa (HV 1; KSA 8:11[182]). ${ }^{17}$ Mientras que aquella está asociada con la explotación (Ausbeutung), la represión (Unterdrückung) y la dominación (Herrschaft) del otro, ésta está asociada con la inoculación ennoblecedora (HH 224), la diferenciación y la pluralización de la vida que surge del encuentro con el otro precisamente como aquella fuerza que no puede ser incorporada y que resiste una incorporación aniquiladora (Einverleibung) (KSA 11:36[22]). Más aún, mientras que en el primer caso la Einverleibung es entendida como un proceso de vida a través del cual se constituyen y preservan totalidades (Ganzheiten) cada vez más poderosas por la aniquilación e incorporación exclusiva del otro; en el segundo, se representa a la Einvereibung como impulsada por una fuerza receptiva y hospitalaria, esto es, una apertura hacia el otro que promueve la pluralización y diversificación de la vida.

La descripción de Nietzsche de los filósofos de la Stoa captura muy bellamente la idea de la encarnación como inclusión aniquiladora del otro. Los estoicos representan una

\footnotetext{
${ }^{15}$ Para una discusión más extensa sobre el problema de la inmunidad y la incorporación en Nietzsche y Esposito, véase Vanessa Lemm, "Nietzsche, Einverleibung and the Politics of Immunity," International Journal of Philosophical Studies, 21 (1) (2013): 3-19 y Nietzsche y el pensamiento politico contemporáneo. Santiago de Chile: Fondo de cultura económica, 2013, 195-214.

${ }^{16}$ Friedrich Nietzsche, Humano, demasiado humano. Vol. II (Opiniones y sentencias varias y El caminante y su sombra). Trad. Alfredo Brotons Muñoz. Madrid: Akal, 1996.

${ }^{17}$ Friedrich Nietzsche, Sobre la utilidad y los perjuicios de la historia para la vida. Trad.

Germán Cano. Madrid: Biblioteca Nueva, 1999.
} 
idea de filosofía entendida como pulsión tiránica de recrear el mundo de acuerdo a su propia imagen. Aquí, la filosofía es una expresión de la voluntad de poder apuntando hacia la creación del mundo, ejemplificada por los filósofos de la Stoa que buscan incorporar (einverleiben) y prescribir (vorschreiben) en la naturaleza sus propios ideales y moralidad (MBM 9). Esta pulsión tiránica de la filosofía no es sino una reflexión de la pulsión de vida, de "todo lo que vive (Alles, was lebt)", es decir, de crecer y devenir más (MBM 230). Nietzsche identifica la "voluntad fundamental del espíritu (Grundwillen des Geistes)" como el poder "de apropiarse de cosas ajenas (Fremdes sich anzueignen)" (MBM 230). En este movimiento de apropiación del mundo exterior (Außenwelt), lo que se ubica en primer plano es el poder igualador de la incorporación. En esta constitución espiritual del mundo puede reconocerse una fuerte inclinación "a asemejar lo nuevo a lo antiguo, a simplificar lo complejo, a pasar por alto o eliminar lo totalmente contradictorio (das Neue dem Alten anzuähnlichen, das Mannichfaltige zu vereinfachen, das gänzlich Widersprechende zu übersehen oder wegzustossen)" (MBM 230). El objetivo del espíritu es incorporar nuevas "experiencias", "ordenar cosas nuevas bajo órdenes antiguos" (Einreihung neuer Dinge unter alte Reihen)" (MBM 230). En otras palabras, el espíritu busca el crecimiento y el sentimiento de un poder que aumenta (Gefühl der vermehrten Kraft). Aquí, la incorporación designa un medio de dominación a través del cual una forma dada de vida extiende su poder sobre otra, incorporando a lo extranjero, nuevo y diferente en una totalidad ya existente, reduciéndolo de este modo a una instancia de lo conocido, viejo, igual e idéntico. En este punto, mi tesis es que la interacción o contienda (agon) que los cínicos escenifican en contra de la vida política y la vida filosófica platónica (ideal ascético) es una ilustración de la "inoculación ennoblecedora" de Nietzsche o encarnación como estrategia de comunidad.

Nietzsche delinea estas dos formas diametralmente opuestas de encarnación sobre la distinción de dos tipos de filósofos y filosofías: una filosofía que necesita a la verdad como medicina relajante para curar la enfermedad y una filosofía en la que la verdad figura como signo de salud. En el primer caso, aquellos que practican la filosofía desde un estado de enfermedad necesitan su verdad como una medicina relajante. En el segundo caso, aquellos que practican la filosofía desde un estado de salud entienden su verdad como una expresión de la abundancia de la fuerzas de la vida. Mientras que en el primero la verdad es un medio de auto-preservación que protege al filósofo de la contingencias de la vida, en el segundo las contingencias de la vida son abrazadas y afirmadas como instancias de la verdad capaces ellas mismas de proporcionar una ocasión para el crecimiento y la expansión transformadora de la vida.

Esta distinción en Nietzsche tiene una fuerte afinidad con la distinción de Foucault entre la tradición platónico-socrática y la tradición cínica (Foucault, 2009, 118ss). Según Foucault, la tradición platónico-socrática está caracterizada por la idea del filósofo como alguien que conduce o guía a los seres humanos hacia la verdad de sus almas entendida 
como la entidad metafísica que uno descubre en la práctica del cuidado de sí. En la segunda tradición, se encuentra la idea de la filosofía como un desafío de la vida en el que hay que probar continuamente la verdad propia al darle un cierto estilo o modalidad a la vida propia. En la primera tradición, la filosofía se ubica bajo el paradigma del conocimiento del alma en el que este conocimiento se convierte en una ontología del yo. En la segunda, en cambio, la filosofía es un desafío, un experimento o prueba de la vida (bios) en el que la vida es materia y objeto de un arte de sí o de una estética de la existencia. Foucault sostiene que los cínicos fueron los primeros que se tomaron verdaderamente en serio el problema de la vida como un objeto del cuidado de sí y, por ello, son el punto de partida de una praxis alternativa de la actividad filosófica (ibíd.).

Bajo el modelo platónico-socrático de la vida filosófica, el objetivo del cuidado de sí apunta a la separación del alma con el cuerpo. Aquí, el alma es entendida como una entidad ontológica distinta del cuerpo. En otras palabras, la idea socrática de la vida filosófica es una idea de la verdad en la que la encarnación de esta última tiene la función inmunitaria de separar la verdad de la vida, el alma del cuerpo, esto es, de aspirar hacia la pureza del alma protegiéndola de la influencia desviante de los instintos y pasiones del cuerpo sobre la capacidad del individuo para hablar francamente. En este punto, el hablar franco deviene un discurso metafísico sobre la naturaleza o esencia humana que sienta las bases para una comprensión ontológica del ser humano desde la cual pueden deducirse una ética o normas de conducta (Foucault, 2009, 147s). El carácter metafísico de la verdad en la idea platónico-socrática de la vida filosófica porta internamente su contienda en contra de la vida política como una retirada hacia la esfera privada tanto del alma individual, como también de un príncipe en particular, en la que el rol del filósofo es guiar o cuidar del príncipe. En contraste con la tradición platónico-socrática, en los cínicos, el hablar franco no está ligado a un discurso metafísico sino más bien a la necesidad de darle una forma visible, pública o común a la vida. Aquí, el hablar franco tiene que definir la forma visible que el humano le da a su vida. Se requiere del "coraje de la verdad" para exponer la propia existencia física al desafío de darle forma o estilo.

\section{Foucault y la política de la comunidad en los cínicos.}

Foucault distingue entre cuatro criterios de la verdadera vida presentes en el pensamiento griego clásico (Foucault, 2009, 200ss). En primer lugar, está la idea de la verdad como lo no-oculto, lo no-disimulado. En otras palabras, lo completamente visible. En segundo lugar, se encuentra la idea de la verdad como aquello que no recibe adición ni suplemento alguno. La verdad es pura y sin mezcla. En tercer lugar, lo verdadero es lo justo, lo correcto (droit), en tanto que recto y opuesto a los desvíos. La verdad como rectitud, pero también como aquello que está en concordancia con la ley (nomos). Por 
último, la verdad es aquello que existe y perdura inalterado y sin cambio. La verdad es incorruptible y siempre idéntica a sí misma. En Platón, estos cuatro criterios están reflejados en su ideal de una vida que no mezcla el bien con el mal, el placer con el sufrimiento, el vicio con la virtud. En contraste con la vida del hombre democrático, la vida filosófica es una vida de pureza y unidad en conformidad con los principios y leyes de la naturaleza. La verdadera vida es una vida soberana sujeta a perfeccionar el dominio de las pasiones del cuerpo, una vida de felicidad y satisfacción absolutas. De acuerdo con Foucault, los cínicos someten este ideal platónico de la vida filosófica como felicidad y bendición a una crítica radical que cuestiona el valor mismo de la vida platónica. Esta crítica se encuentra reflejada en el principio cínico de "cambiar el valor de la moneda" (Foucault, 2009, 209). Para Foucault, la filosofía de los cínicos es una filosofía de la ruptura, la interrupción y la transvaloración.

Desde mi perspectiva, esta transvaloración de los valores y exteriorización de la filosofía también puede entenderse como un intento por convertir a la filosofía en tanto que dispositivo inmunitario en un vehículo de la comunidad. Los cínicos pusieron en acto lo que llamo estrategia de comunidad. La comunidad remite aquí al proceso por medio del cual se erige una defensa en contra del exceso de inmunidad y que, en consecuencia, conduce hacia una liberación auto-inmunitaria del munus o lo común. Esta estrategia autoinmunitaria describe bastante bien la manera de proceder de los cínicos: los cínicos primero adoptan un principio inmunitario (por ejemplo, las cuatro características de la verdadera vida filosófica) para luego encarnarlo como una forma de vida en la que la práctica del cuidado de sí y el hablar franco vuelcan al yo hacia el otro (munus), en vez de separarlo del cuerpo y del cuerpo de los otros. Esta encarnación auto-inmunitaria es una especie de defensa en contra del principio inmunitario mencionado más arriba. Ésta es la paradoja del "escándalo" de la verdad cínica: ella conduce a su exclusión radical y violenta de parte de la filosofía oficial e instituida, pero, al mismo tiempo, esta exclusión inmunitaria de los cínicos del lado de la polis también conduce, paradójicamente, a la exclusión de los principios de verdad que ellos encarnan y que de otro modo hubiesen sido aceptados como doctrina. Al excluir a la encarnación cínica, la polis abre el horizonte para una transformación de los valores, la alteración de sí y de la polis misma. El resultado es el "escándalo" que surge una vez que la encarnación cínica deshace las inmunidades de la polis y de la vida filosófica platónica y abre el horizonte de una verdadera vida alterada, esto es, la verdadera vida de la comunidad.

Los cínicos alteran y transvaloran la idea de la verdadera vida como vida no-disimulada por medio de lo que Foucault llama el "escándalo de la verdad" (Foucault, 2009, 233). La regla de la no-disimulación deja de ser la aplicación de una conducta o principio ideal y deviene la manifestación, la "mise en scène" de la materialidad cotidiana al conducir una vida radicalmente pública, expuesta y visible a todos en todo momento. Los cínicos probaron por medio de su forma de vida que la vida no le per- 
tenece a nadie y le pertenece a todos simultáneamente. La vida es munus, es decir, radicalmente común. Paralelamente, la aplicación radical del principio de no-disimulación produce una inversión de este mismo principio mostrando con ello que la vida de los cínicos, que es una vida verdaderamente fiel a la idea de la verdad como nodisimulación, es una vida que siempre está en proceso de devenir otra, diferente y extraña. En consecuencia, la vida de los cínicos está siempre cambiando de identidad sin poder nunca permanecer idéntica a sí misma.

De acuerdo a los cínicos, la vida refleja - y es - todo lo que la naturaleza le ha dado a la vida. Por ello, lo que la naturaleza le ha dado al ser humano no puede ser algo malo o rechazable, excluible y eliminable de la vida pública de la polis. Esta actitud está en evidente contraste con las tradiciones estoica y platónico-socrática en las que todo lo vinculado a la naturaleza, el cuerpo, las pasiones, los deseos y la vida es excluido de la vida pública de la polis y retrotraído hacia la esfera privada. Los cínicos afirman la naturaleza, la vida y sus dones como lo irreductiblemente otro, y es esta otredad lo que se manifiesta en la verdadera vida de los cínicos. En última instancia, los cínicos enseñan que se nace cínico y que, en consecuencia, no se puede devenir cínico por medio de la educación y la cultura: esto es tanto una encarnación literal de la idea platónico-socrática de vivir de acuerdo al derecho o ley natural, como también una inversión de la afirmación platónica que sostiene que uno sólo se convierte en filósofo por medio de un arduo proceso de educación (a su vez diferente de la educación que la ciudad le proporciona a sus ciudadanos por medio de la poesía trágica). Los cínicos abolen la división público/privado al disolver las barreras inmunitarias de la civilización, abriendo de este modo la posibilidad de una vida pública que sea verdaderamente comunal. Desde la perspectiva de los cínicos, el problema no es la naturaleza sino los dispositivos inmunitarios de la civilización tales como las costumbres, las convenciones, y las opiniones humanas que primero degradan la vida y la naturaleza para luego excluirlas y expulsarlas de la polis. Cuando el principio de la verdad como no-disimulación es encarnado por la zoe, llevar una verdadera vida exige rechazar todos los límites y barreras tradicionales de la vergüenza, ${ }^{18}$ puesto que lo que el ser humano ha recibido de la naturaleza debe ser transvalorado antes que excluido y afirmado como un bien en lugar de ser excluido como un mal. A través de su forma de vida, los cínicos muestran que la naturaleza no es algo de lo que haya que avergonzarse sino que, por el contrario, un don que necesita ser apreciado y afirmado (Foucault, 2009, 234). La vida de los cínicos refleja una revaluación de la zoe que libera a los principios de la no-disimulación de todas las ideas convencionales de la vergüenza.

\footnotetext{
${ }^{18}$ Sobre las implicancias políticas de la superación de la vergüenza por parte de los cínicos, esto es, "la punta (Spitze) política de la ofensiva quínica", véase principalmente Sloterdijk, Crítica de la razón cínica, 263ss.
} 
Con respecto a la idea de la verdad como independencia sin mezcla reflejada en una vida independiente, sin ningún suplemento, inalterada, y perfectamente idéntica a sí misma, los cínicos operan una inversión similar al encarnar exactamente el mismo principio. En Platón, esta idea se conoce como la vida de pureza, belleza y perfección de un alma que se ha separado completamente del cuerpo y la vida material. En los estoicos y epicúreos, esta idea se convierte en la idea de la independencia, la auto-suficiencia y el autogobierno. En los cínicos, por el contrario, la vida de independencia cobra la forma de una vida indiferente reflejada en la figura de una pobreza radical que, de acuerdo a Foucault, es real, activa e infinita (Foucault, 2009, 237). Esta pobreza es real en la medida en que no se contenta simplemente con la idea de la independencia en tanto que indiferencia frente a lo que pueda o no pueda ocurrir, esto es, frente a la esfera de la contingencia. Por el contrario, la pobreza es un desafío continuo que exige resistencia y coraje para vivir de acuerdo al principio de independencia. Es en este sentido que la pobreza es infinita o indefinida: los cínicos se esfuerzan continuamente por producir una reducción de los suplementos y las necesidades, hasta que alcanzan o encuentran lo que es verdaderamente indispensable para la vida. La pobreza en cuanto tal exige un proceso continuo de auto-experimentación y trabajo sobre sí mismo.

Nuevamente, los resultados de esta encarnación de la idea de la verdad como independencia son radicales y paradójicos ya que, en vez de producir una vida harmónica de paz y belleza, esta encarnación produce una vida caracterizada por la fealdad y una dependencia humillante. Los cínicos revalorizan las necesidades más básicas de la vida, exponiéndose y haciéndose completamente dependientes mientras que, paradójicamente, llevan una vida de independencia, esto es, una vida sucia y repugnante definida por la miseria y la humillación (Foucault, 2009, 239). De aquí proviene la famosa comparación entre la vida de los cínicos y la vida de los perros. Podemos observar una vez más cómo es que la idea de munus se encuentra activa en la vida de los cínicos en la medida en que están completamente expuestos y dependen de los dones de los demás hasta el punto de no poder preservarse más a sí mismos. Los cínicos destruyeron y superaron todos los dispositivos inmunitarios de auto-preservación y están completamente sujetos a la buena voluntad de los demás (que, por ejemplo, les dan comida).

La materialidad y fragilidad de la vida, expuesta en el estilo de vida de los cínicos, es reafirmada por ellos también en la idea de la esclavitud. Mientras que la esclavitud es rechazada por la polis como la forma de vida más básica, privada de libertad e inhumana, los cínicos la afirman y aprecian. La esclavitud refleja su creencia de que la vida, toda vida, no puede nunca ser completamente autosuficiente y autogobernada. La verdadera independencia descansa en el don de otro, en la relación comunal entre los humanos y la naturaleza en la que lo que se da cae fuera de la lógica de la utilidad y el cálculo. Aquí, la vida se mantiene en comunidad con el otro antes que por medio de dispositivos de inmunización cuya función es separar. 
Finalmente, al encarnar el principio de independencia bajo la forma de la pobreza, los cínicos se convierten en sujetos con mala reputación. Para los cínicos, la práctica sistemática de la humillación, los insultos y la deshonra se invierten en una conducta positiva con valor y sentido. Mientras más sea la humillación que pueda tolerarse por el otro, mayor es el orgullo de los cínicos, puesto que el cínico prueba por medio de su ejemplo de vida que él es el verdadero soberano y dueño de sí mismo, habiendo resistido y superado incluso lo peor, a saber, ser excluido de la vida pública de la polis. El cínico demuestra que la mayor comunidad de la vida cósmica es aquello que preserva su vida y no la polis (Foucault, 2009, 242).

La tercera idea de la verdad como vida de rectitud en conformidad con el logos y el nomos, deviene en los cínicos una vida en conformidad con la ley natural. En tanto que opuesta a las convenciones, la naturaleza es el único estándar aceptable para medir la vida (Foucault, 2009, 243). Aquí, el estándar de la naturaleza es la animalidad del ser humano. Mientras que la animalidad del ser humano ha sido tradicionalmente excluida, los cínicos la elevan hasta el mayor grado de realización humana. La animalidad se convierte en un modelo de vida y conducta individual basado en la idea que el animal humano tampoco debiese necesitar aquello que los animales no necesitan. Si previamente las necesidades de la vida eran tomadas por un signo de debilidad que somete al ser humano a la esclavitud, al aplicar el estándar de la animalidad, esta idea es invertida y liberada. Ahora el ser humano es liberado de las necesidades ya que todas las necesidades de la naturaleza pueden satisfacerse también por la naturaleza y el ser humano no necesita otra cosa más allá de esto. Vivir de acuerdo al estándar de la animalidad es liberador (Foucault, 2009, 245). Según Foucault, la animalidad en los cínicos es una forma reduccionista pero también prescriptiva de la vida. La animalidad no es considerada como algo simplemente dado, sino como una tarea, un desafío ético de vivir de acuerdo a las necesidades de la animalidad propia. La animalidad se convierte en el modelo moral como también en el modelo material de la existencia. Como tarea o desafío, la animalidad deviene un principio de la cultura. En la vida de la zoe, es decir, el bios de la zoe, el bios no se le impone a la vida animal (zoe) como una segunda naturaleza, sino que la zoe genera un bios a partir de sus propios recursos.

Por último, tenemos la idea de la verdadera vida como vida soberana. En el ideal socrático, la vida soberana es una vida en completa posesión de sí misma, en la que ningún fragmento o elemento del yo escapa a su dominio o control. La vida soberana es una vida de placer, una vida auto-cumplida. Al mismo tiempo, esta vida es beneficiosa para otros y conlleva una obligación representada típicamente tanto por la relación entre el maestro y el discípulo como por la imagen del héroe o genio de la cultura que es un benefactor de toda la humanidad. En este contexto, encontramos al tema del cínico de Foucault como un anti-monarca, un anti-rey que no recibe su reino a través de circunstancias exógenas como en el caso de Alejandro Magno, sino que a través 
de la voluntad de los dioses. El cínico no se convierte en rey por medio de la educación y el cultivo, sino que nace rey simplemente por ser humano. En la comprensión cínica de la soberanía, ser elegido por un dios conlleva una obligación, una misión, a saber, cuidar de los demás. Cuidar de los demás no significa simplemente guiar al otro por medio de discursos u ofrecer un ejemplo de vida, significa en cambio cuidar verdaderamente de ellos, incluso si esto equivale a sacrificar la vida propia. Es una ardua misión que exige renunciar a sí mismo. Interesantemente, Foucault señala que el modelo más habitual de intervención de los cínicos es el médico en tanto que opuesto al legal. Los cínicos curan a los demás de manera que puedan volverse verdaderamente felices y saludables. Esta intervención es difícil y requiere de agresividad y disposición para luchar y combatir. El cínico no le hace un bien a los demás al llevar una vida ejemplar, sino que al luchar por ellos. Él es útil porque muerde y ataca. El cínico lucha por la humanidad entera con el objetivo de transformar el mundo, a sus actitudes y valores morales, pero también sus hábitos, convenciones y formas de vida (Foucault, 2009, 258). La última tarea del cínico consiste en dirigirse a toda la humanidad al luchar con, a favor de, y en algunas circunstancias incluso contra ella, con miras a revolucionar el mundo (Foucault, 2009, 270). Tal tarea sólo puede ser fijada por un dios y vivir en conformidad con ella supone encarar los cuatro desafíos de la verdadera vida tal cómo los entienden los cínicos. En consecuencia, los cínicos se convierten en los misioneros universales de la humanidad que la cuidan y la vigilan. Los cínicos se hacen responsables por la humanidad en su conjunto, por toda la especie humana (Foucault, 2009, 277). Foucault insiste en que en los cínicos, el cuidado de sí, del mismo modo que la conducta propia, es inseparable del cuidado y la conducta de los demás, de manera que para los cínicos transformar el mundo equivale a cambiar el modo en que los humanos se conducen a sí mismos en el mundo (Foucault, 2009, 287).

Al seguir estos cuatro principios o características de la verdadera vida y sus reversos en las encarnaciones cínicas de estas características, Foucault se pregunta si acaso los cínicos han demostrado exitosamente que la verdadera vida filosófica es una vida distinta que la que lleva la mayoría de los hombres de la polis y, en particular, el filósofo. La verdadera vida es paradójica y radicalmente distinta de todas las formas tradicionalmente aceptadas de existencia (Foucault, 2009, 226). Alternativamente, mi hipótesis es que la otredad de los cínicos no es otra cosa que lo común a la vida política y la vida filosófica socrática que, sin embargo, ninguna de estas dos formas de vida reconoce. La vida política inmuniza a la doxa al proteger a la opinión frente a la verdad, y la vida filosófica socrática inmuniza a la verdad al protegerla contra la opinión. La forma de vida cínica supera esta división entre la vida política y la vida filosófica al mostrar la comunidad entre ambas formas de vida, anulando de este modo su mutua inmunización. En consecuencia, la disputa cínica de la vida filosófica platónicosocrática despunta como un intento por popularizar a la filosofía en tanto que destruye 
la inmunidad de la verdad. Por el contrario, la contestación cínica a la vida política se muestra como un intento por establecer el cosmopolitismo debido a que éste acaba con las defensas inmunitarias de la polis contra los extranjeros.

Quizá sea en estas dos características - popularizar a la vida filosófica y cosmpolitizar a la vida política - donde se encuentra la clave del famoso encuentro entre Alejandro Magno, estudiante de Aristóteles, y el cínico Diógenes. Después de todo, Alejandro Magno puso fin a la hegemonía de la polis griega al establecer su imperio helenista y cosmopolita, lo cual podría explicar su interés en el ataque de Diógenes contra la inmunidad de la polis en nombre de una nueva política mundial o cosmopolitismo. Por otra parte, cuando Alejandro Magno llega a ver a Diógenes para ofrecerle cualquier cosa que éste quiera, y el cínico responde que sólo quiere que Alejandro se mueva y deje de taparle el sol, el mensaje también es claro: el sol representa a la divinidad; los rayos del sol son la elección de dios de su verdadero representante en la tierra, y estos rayos son para Diógenes, no para Alejandro. Los soberanos políticos son meras nubes pasajeras que interfieren con el verdadero iluminismo de la forma de vida cínica.

Traducción del inglés por Matías Bascuñán.

\section{Bibliografía}

Arendt, Hannah. 2011. La vida del espíritu. Barcelona: Édiciones Paidós.

Esposito, Roberto. Bios: biopolitica y filosofía. Buenos Aires: Amorrotu. 2006.

Esposito, Roberto. 2003. Communitas: origen y destino de la comunidad. Trad. Carlo R. Molinari Marotto. Buenos Aires: Amorrortu.

Derrida, Jacques. 1978. Éperons: Les styles de Nietzsche. Paris: Flammarion.

Foucault, Michel. 2009. Le courage de la vérité. Le gouvernement de soi et des autres II, Cours au Collège de France 1983-1984. Frédéric Gros, ed. Paris: Gallimard-Le Seuil-Hautes Études.

Foucault, Michel. 2008. Le gouvernement de soi et des autres: Cours au Collège de France 1982-1983, François Ewald, Alessandro Fontana y Frédéric Gros, eds. Paris: Gallimard-Le Seuil-Hautes Études.

Gehlen, Arnold. 1969. Moral und Hypermoral: Eine pluralistische Ethik. Frankfurt: Athenäum Verlag.

Glucksmann, André. 1981. Cynism et passion. Paris: Bernard Grasset, 1981.

Goulet-Cazé, Marie-Odile. 1982. "Un syllogisme stoïcienne sur la loi dans la doxographie de Diogène le Cynique a propos de Diogène Laërce VI 72," Rheinisches Museum für Philologie 115: 214-240.

Heinrich, Klaus. 1966. Parmenidis and Jona: Vier Studien über das Verhältnis von Philosophie und Mythologie. Frankfurt: Surhkamp Verlag.

Lemm, Vanessa. 2013. "Nietzsche, Einverleibung and the Politics of Immunity," International Journal of Philosophical Studies, 21 (1): 3-19. 
Lemm, Vanessa. 2013a. Nietzsche y el pensamiento politico contemporáneo. Santiago de Chile: Fondo de cultura económica.

Nietzsche, Friedrich. 2007. Más allá del bien y del mal: Preludio de una filosofía del futuro. Trad. Andrés Sánchez Pascual. Madrid: Alianza Editorial.

Nietzsche, Friedrich. 1988. Sämtliche Werke, Kritische Studienausgabe in 15 Bänden. Berlin: de Gruyter Verlag.

Nietzsche, Friedrich. 1999. La ciencia jovial. Trad. José Jara. Caracas: Monte Ávila Latinoamericana.

Nietzsche, Friedrich. 1997. La genealogía de la moral. Trad. Andrés Sánchez Pascual. Madrid: Alianza.

Nietzsche, Friedrich. 1996. Humano, demasiado humano. Vol. II (Opiniones y sentencias varias y El caminante y su sombra). Trad. Alfredo Brotons Muñoz. Madrid: Akal.

Nietzsche, Friedrich. 1999c. Sobre la utilidad y los perjuicios de la historia para la vida. Trad. Germán Cano. Madrid: Biblioteca Nueva.

Marzocca, Ottavio. 2013. "Philosophical Parresia and Transpolitical Freedom," Foucault Studies 15: 129-147.

Moles, John L. 1996. “Cynic Cosmopolitanism.” In: The Cynics: The Cynics Movement in Antiquity and its Legacy,” eds. R. Bracht Branham and Marie-Odile Goulet-Cazé, 105-120. Berkeley: University of California Press.

Tillich, Paul. 1952. The Courage to be. New Haven: Yale University Press.

Sloterdijk, Peter. 2005. Crítica de la razón cínica. Madrid: Editorial Siruela.

\section{Vanessa Lemm}

School of Humanities and Languages

University of New South Wales

Sydney NSW 2052, Australia

v.lemm@unsw.edu.au

Instituto de Humanidades

Universidad Diego Portales

Santiago de Chile, Chile 